\title{
Hyperalgesia in semantic dementia
}

\author{
Leonardo Caixeta', Vânia Lúcia Dias Soares², Cândida D. Soares³
}

There are very few studies addressing pain mechanisms in frontotemporal lobar degeneration (FTLD), as well as the possible contributions that the study of the neurobiological basis of pain in dementia can confer to the knowledge of general pain physiopathology itself $f^{1,2}$.

Semantic dementia (SD) is a form of FTLD in which patients progressively lose conceptual knowledge about the world, affecting their ability to understand sensory stimuli such as non-verbal sounds, tastes, and smells ${ }^{3}$.

A 60-year-old right-handed, businessman, presented 4 year history of word finding difficulty together with impaired word comprehension. Day-to-day and personal autobiographic memories were unaffected. He did not present depression signs. Patient has developed marked histrionic traits: if brushed by a family member he may react as if in severe pain, an exaggerated reaction to tactile stimuli. He keeps claiming for long time after any bruising, even the very mild ones. Orthopedic investigation resulted negative many times. During physical exam, more precisely during face tapping (to elicit prim- itive reflexes), he became angry with the manipulation, assumed that behavior as violence, reacting with obscenity and prohibiting me to keep the neurological exam even despite all my warnings that was important to me to continue my job in order to elucidate his health problem. In the neurological exam, except for the alterations in semantic memory, no other abnormalities were seen. His MRI is showed in Figure. A SPECT scan showed bilateral hypoperfusion in temporal lobes.

His score on the MMSE was 26/30. Digit Span was 7 forward, 4 backward. His day-to-day memory was unaffected. Constructional ability was preserved. His spontaneous speech was fluent and anomic with normal syntax, phonology and prosody. On verbal fluency he did 3 animals in one minute. Performance on sentence repetition of Boston Diagnostic Aphasia Examination was normal. Comprehension of syntax was normal, however, oral and written comprehension of single words were impaired.

Our patient presents an exaggerated reaction to tactile stimuli. Patients with SD were also significantly more likely than
Correspondence Leonardo Caixeta

Av. Cristo Rei, esq. c/ Rua J63, nº 626 quadra 114 / lote 12 / setor Jaó 74674-290 Goiânia G0 - Brasil E-mail: leonardocaixeta1@gmail.com

Received 26 October 2010

Received in final form 6 December 2010 Accepted 13 December 2010
Figure. MRI (coronal T1 slice) revealing bilateral temporal atrophy, more marked on the left, including hippocampal atrophy, most intense on the left side.

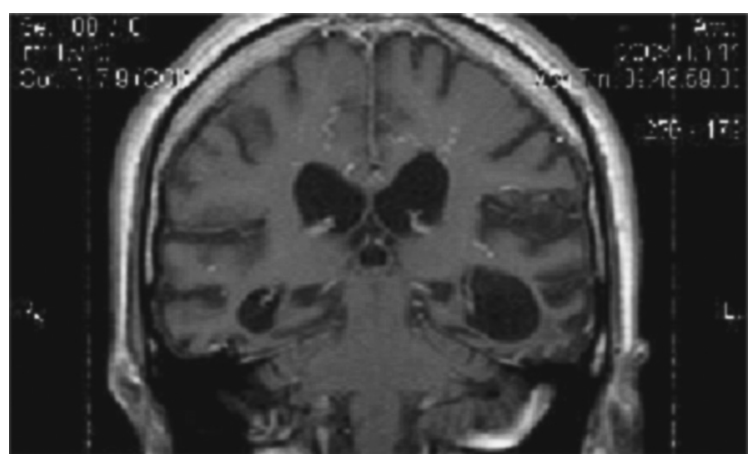

\section{HIPERALGESIA NA DEMÊNCIA SEMÂNTICA}

'M.D., Ph.D. Associate Professor, Faculty of Medicine, Federal University of Goiás, Goiânia GO, Brazil. Coordinator of the Behavioral and Cognitive Neurology Unit of the Hospital das Clínicas, Federal University of Goiás, Goiânia G0, Brazil; ${ }^{2}$ Neuropsychologist, Member of Behavioral and Cognitive Neurology Unit of the Hospital das Clínicas, Federal University of Goiás, Goiânia GO, Brazil; ${ }^{3}$ Speech Pathologist, Member of Behavioral and Cognitive Neurology Unit of the Hospital das Clínicas, Federal University of Goiás, Goiânia GO, Brazil. 
patients with frontotemporal dementia (FTD) to show an exaggerated reaction to heat and cold ${ }^{4,5}$.

Reduced and exaggerated responses to sensory stimuli seem not to be mutually exclusive since our patient with SD with histrionic traits reacts melodramatically to neutral sensations, such as light touch, but also fail to show an appropriate withdrawal reaction to painful stimuli. This suggests that exaggerated reactions are unlikely to reflect genuine hypersensitivity, along a pain threshold continuum, but rather may have a distinct underlying substrate, maybe bilateral temporal atrophy, the most relevant neuropathological find in SD.

We hypothesized that impaired meaning attribution to sensory stimuli in SD would render difficult the task of distinguishing relevant from irrelevant stimuli, of determining to which environmental features the patient should attend and which ignore. This represents a 'se- mantic' impairment in the interpretation of pain as the cause of exaggerated reaction to tactile stimuli presented in SD. It might be conjectured that such reactions could arise as a secondary consequence of patients' semantic disorder, as previously addressed ${ }^{5}$.

\section{REFERENCES}

1. Zwakhalen SM, Hamers JP, Abu-Saad HH, Berger MP. Pain in elderly people with severe dementia: a systematic review of behavioural pain assessment tools. BMC Geriatr 2006;6:3-10.

2. Scherder EJ, Sergeant JA, Swaab DF. Pain processing in dementia and its relation to neuropathology. Lancet Neurol 2003;2:677-686.

3. Caixeta L, Mansur LL. Demência semântica: avaliação clínica e de neuroimagem: relato de caso. Arq Neuropsiquiatr 2005;63:348-351.

4. Snowden JS, Bathgate D, Varma A, Blackshaw A, Gibbons ZC, Neary D. Distinct behavioural profiles in frontotemporal dementia and semantic dementia. J Neurol Neurosurg Psychiatry 2001;70:323-332.

5. Snowden JS, Neary D, Mann DMA. Fronto-temporal degeneration: frontotemporal dementia, progressive aphasia, semantic dementia. London: Churchill Livingstone, 1996:91-114. 